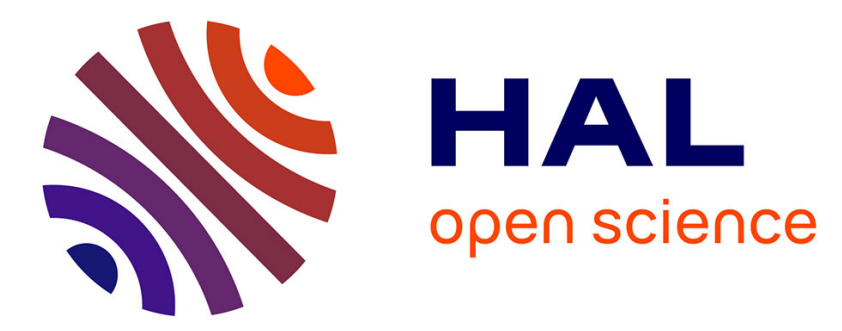

\title{
Thiomers and their potential applications in drug delivery
}

Kifayat Ullah Ullah Shah, Shefaat Ullah Shah, Naz Dilawar, Gul Majid Khan, Stéphane Gibaud

\section{- To cite this version:}

Kifayat Ullah Ullah Shah, Shefaat Ullah Shah, Naz Dilawar, Gul Majid Khan, Stéphane Gibaud. Thiomers and their potential applications in drug delivery. Expert Opinion on Drug Delivery, 2016, 14 (5), pp.601-610. 10.1080/17425247.2016.1227787 . hal-01377809

\section{HAL Id: hal-01377809 \\ https://hal.science/hal-01377809}

Submitted on 11 Oct 2016

HAL is a multi-disciplinary open access archive for the deposit and dissemination of scientific research documents, whether they are published or not. The documents may come from teaching and research institutions in France or abroad, or from public or private research centers.
L'archive ouverte pluridisciplinaire $\mathbf{H A L}$, est destinée au dépôt et à la diffusion de documents scientifiques de niveau recherche, publiés ou non, émanant des établissements d'enseignement et de recherche français ou étrangers, des laboratoires publics ou privés. 


\title{
Thiomers and their potential applications in drug delivery
}

\author{
Kifayat Ullah Shah ${ }^{1}$, Shefaat Ullah Shah ${ }^{2 \& 3}$, Naz Dilawar ${ }^{1}$, Gul Majid Khan ${ }^{1}$ and Stéphane Gibaud ${ }^{3}$ \\ ${ }^{1}$ Department of Pharmacy, Quaid-e-Azam University, Islamabad, Pakistan \\ ${ }^{2}$ Faculty of Pharmacy, Gomal University, D.I.Khan, Pakistan \\ ${ }^{3}$ Université de Lorraine, EA 3452/CITHEFOR, 5 rue Albert Lebrun (Faculté de Pharmacie), F-54000 Nancy, \\ France
}

\author{
Kifayat Ullah Shah \\ Address: Department of Pharmacy, Quaid-e-Azam Univeristy, Islamabad Pakistan \\ Academic qualification: Phd \\ Job titles: Assistant Professor \\ Phone number: 0092-3325542722 \\ Fax number:Nil \\ Email address: kushah@qau.edu.pk
}

\section{Shefaat Ullah Shah}

Address: Department of Pharmaceutics, Faculty of Pharmacy, Gomal University, D.I.Khan, KPK, Pakistan And Faculté de Pharmacie - 5, rue Albert Lebrun - 54000 Nancy - France

Academic qualification: $\mathrm{PhD}$

Job titles: Lecturer

Phone number: 0092-3365140682

Fax number:Nil

Email address: shefaatbu@gmail.com

\section{Naz Dilawar}

Address: Department of Pharmacy, Quaid-e-Azam Univeristy, Islamabad Pakistan Academic qualification: M.Phil

Job titles: M.Phil Scholar

Phone number: 0092-3339645202

Fax number: Nil

Email address: nazdilawar@gmail.com

\section{Gul Majid Khan}

Address: Department of Pharmacy, Quaid-e-Azam Univeristy, Islamabad Pakistan

Academic qualification: $\mathrm{PhD}$

Job titles: Professor

Phone number:0092-3009091688

Fax number: Nil

Email address: gmkhan@qau.edu.pk

\section{Stéphane Gibaud}

Address: Faculté de Pharmacie - 5, rue Albert Lebrun - 54000 Nancy - France

Academic qualification: $\mathrm{PhD}, \mathrm{PharmD}$

Job titles: Maître de conférences - Praticien Hospitalier

Phone number: + 33383682310

Email address: stephane.gibaud@univ-lorraine.fr 


\title{
Thiomers and their potential applications in drug delivery
}

\begin{abstract}
:
Introduction: Thiomers are the product of the immobilization of sulfhydryl-bearing ligands onto the polymer backbone of a conventional polymer, which results in a significant improvement in mucoadhesion, in situ gelation and efflux inhibition compared with unchanged polymers. Because of thiol groups, thiomers have more reactivity and enhanced protection against oxidation. Since the late 1990s, extensive work has been conducted on these promising polymeric excipients in the pharmaceutical field.
\end{abstract}

Areas Covered: This review covers thiomers, their classification and their different properties. Various techniques for the synthesis, purification and characterization of thiomers are described in detail. This review also encompasses their various properties such as mucoadhesion, permeation enhancement, in situ gelation and efflux inhibition, as well as different formulations based on thiomers. In addition to the use of thiomers as multifunctional excipients, this review also encompasses their use as drugs.

Expert Opinion: The synthesis is realized by linkage of sulfhydryl-bearing ligands but reported methods give low yields. Higher degrees of modification are not necessary and would probably lead to extreme changes in properties. Nevertheless, an accurate characterization of the final product is important. The scale-up procedure for industrial manufacturing has been adapted to produce GMP materials; Lacrimera ${ }^{\circledR}$ eye drops have already entered the European market.

Keywords: Mucoadhesion, Oral delivery, Preactivated thiomers, $S$-nitrosothiomers, Thiomers,

\section{Article highlights}

- Several methods have been described to produce thiomers, but the yields of these reactions are low

- An accurate characterization of the final products is important

- Thiomers have good mucoadhesive properties

- Thiomers have been used to enhance the permeation of drugs across biological barriers

- Thiomers have efflux pump inhibiting properties

- Some thiomers have in situ gel properties

- Some thiomers can be used to produce tablets, nanoparticles or microparticles

- From these thiomers, S-nitrosothiomers have been synthesized and proposed as new NO donors 


\section{Introduction}

Thiolated polymers, also referred to as thiomers, have encouraged the development of various fields of polymer-based medicine [1-3]. Thiomers or thiolated polymers are macromolecules bearing free thiol groups on the polymer backbone. The immobilization of sulfhydryl-bearing compounds (SBC) onto the backbone of well-developed polymeric excipients such as chitosan (CS) and poly (acrylates) may lead to the generation of these thiomers [4-6] as illustrated in figure 1. The formation of inter- and intramolecular disulfide bonds gives strong cohesive properties to thiomers, leading to comparatively advanced stability and consequently extended disintegration times and drug release from different dosage forms such as tablets, micro particles and gels [7]. In contrast to unmodified polymers, thiomers illustrate advantages in mucoadhesion and enzyme and efflux inhibition. The use of thiolated polymers or thiomers might overcome some prominent challenges in the applications of macromolecules as therapeutic agents including deficiencies in efficiency, safety and detailed delivery approaches [8].

There has been substantial growth in the number of commercially available bioactive macromolecular therapeutic agents, such as proteins and peptides, due to current improvements in the pharmaceutical/biotechnology field. Due to their cost, these drugs are used in the treatment of major conditions such as acquired immunodeficiency syndrome (AIDS), cardiovascular disorders, hepatitis and cancer etc.[9]. Macromolecules have poor oral bioavailability, and parenteral routes are necessary. Because this latter approach is often linked with pain, fear and risks, it is of particular importance for pharmaceutical companies to make alternative routes available for drug administration. This is especially important for long-term treatments [8]. To overwhelm the targeted body diffusion barrier, drug delivery systems must possess specific properties. The bioavailability of macromolecular drugs has certain limitations due to the diffusion barriers offered by the mucosal gel layer wrapping mucosal membranes followed by the absorption barriers surrounding epithelial layers and efflux pumps, which are aided by enzymatic barriers. The polymeric excipients for drug delivery must possess certain prominent features to overwhelm these barriers, including mucoadhesive [10-12] and protective activity [13; 14], drug release control $[15 ; 16]$, improved solubility [17; 18], and permeation and uptake enhancing properties [19-21]. However, thiols groups are unstable in solution (oxidized at $\mathrm{pH} \geq 5$ ) and some authors have demonstrated that protective substructures can be introduced to overcome this shortcoming [22]. This idea has recently led to a second generation of thiomers ("preactivated thiomers") with improved properties (e.g., mucoadhesive properties) [23] (Figure 1).

Finally, thiomers can be bound to nitric oxide to act as new NO donors [24; 25] (Figure 1). 


\section{Types and synthesis of thiomers}

\subsection{First generation}

Numerous naturally occurring polymers, such as CS [26; 27], cellulose [28], hyaluronic acid [29], gelatin [30], collagen [31], and synthetic polymers, such as poly(acrylic acid) (PAA) [32], are commonly used as thiomer precursors. Thiomers are characterized as cationic, anionic and non-ionic based on the chemical structure of these parent molecules.

Cationic thiomers are prepared by immobilizing SBCs onto the 2-amino position of the glucosamines in the polymer chain. These thiomers are based on CS, such as chitosan-cysteine (CS-Cys) and chitosanthioglycolic acid (CS-TGA) etc. [33]. The carboxylic acid group of Cys or thioglycolic acid (TGA) can react with the $-\mathrm{NH}_{2}$ group of $\mathrm{CS}$, but the reaction has to be mediated by a carbodiimide. Other SBCs, such as N-acetylcysteine, 6-mercaptonicotinic acid and glutathione, can form amide bonds with chitosan [34; 35]. The cationic property not only comes from various groups of the SBCs (e.g., $\mathrm{NH}_{3} / \mathrm{NH}_{4}{ }^{+}$ from amino acids) but also from the unreacted $\mathrm{NH}_{3}$ groups of the glucosamine. To date, described procedures have had a low yield (e.g., 25\% for chitosan $-\mathrm{GSH}=558 \mu \mathrm{mol} / \mathrm{g}$ ) [24]). Amino acids can be affected by unintended reactions [36] that could be limited by protection of the carboxylic group. Nevertheless, some authors have used TGA as the SBC, and because this SBC is not an amino acid, unintended reactions are not possible; however, there is also a very low yield $(<40 \mu \mathrm{mol} / \mathrm{g})$ [37].

Furthermore, there is a second method that is sometimes used to modify CS. With the chemical reaction between CSs and 2-iminothiolane (Traut's reagent), a cationic amidine conjugate chitosan-4thiobutylamidine (CS-TBA) is produced [38]. In another study, to achieve better stability and properties similar to those of chitosan-4-thiobutylamidine, chitosan-thioethylamidine (TEA) was synthesized by a similar mechanism [39]. All the procedures gave quite similar yields. Hence, it is possible that this issue is due to limited accessibility to the amine groups (i.e., steric hindrance).

For anionic thiomers, carboxylic acid groups are present on the polymeric substrates. Hence, the immobilization of the SBCs on these polymers can also be mediated by carbodiimides and is possible if the SBC bears a primary amine group. Examples include carboxymethylcellulose-cysteine (CMC-Cys) and alginate-cysteine (ALG-Cys) [40]. The reaction yields are also very low.

To date, these reactions are widely used to obtain thiomers and their low yields are probably not so important. It is supposed that higher degrees of modification would probably lead to extreme changes in properties. 
Expert Opinion on Drug Delivery - http://dx.doi.org/10.1080/17425247.2016.1227787

Finally, to achieve thiolation of polysaccharides exhibiting neither carboxylic acid nor primary amino groups (e.g., nonionic polymers), other methods can be used:

\section{Insert Figure 2}

1) Periodate cleavage of vicinal thiol followed by conjugation with amino acids is an advantageous technique (Figure 2). Thiomers are synthesized under fairly simple and mild conditions by covalently attaching SBCs bearing a $-\mathrm{NH}_{2}$ to the polymer backbone. Recently, Madgulkar et al. [41; 42], synthesized a novel mucoadhesive derivative of xyloglucan via oxidation of xyloglucan followed by conjugation with the amino groups of Cys as shown in figure 2. Sodium periodate was used to oxidize the hydroxyl groups located at carbon 2 and 3, resulting in the formation of different reactive groups having more rotational autonomy along the polymer backbone. The authors found that compared with the glucose remaining on the key chain, the xylose and galactose deposits on the lateral chains were more ideal for oxidation, which may be due to the dexterity of pendant side sugar deposits compared to glucose residues on the main chain. It was also found that the vicinal $-\mathrm{OH}$ group of the $\beta-(1 \rightarrow 4)-$ linked Dglucopyranose backbone was in the trans state, which was kinetically less promising for periodate oxidation compared with the prime (cis) conformation detected in galactose and xylose residues.

2) A nonionic polysaccharide such as hydroxyethylcellulose (HEC) can be transformed into a positively charged thiomer after oxidation of the proximal hydroxyl groups to aldehyde followed by conjugation of Cys to the same aldehyde groups using reductive amination reactions [43]. Bromination of HEC is also used to synthesize non-ionic thiomers, and then, the bromine of bromohydroxyethylcellulose (Br-HEC) is substituted with thiol groups by treating Br-HEC with thiourea yielding $131.58 \pm 11.17 \mu$ mol of thiol groups per gram of polymer [44]. The synthesized thiomers are primarily purified using dialysis followed by freeze-drying under reduced pressure. These polymers can also be precipitated using organic solvents, such as Ellman's reagent, for quantification of the immobilized thiol groups [35].

\subsection{Second generation: preactivated thiomers}

The synthesis of preactivated thiomers was recent reviewed by Ijaz et al. [35]. The protective substructures are pyridyl thiol groups derivatives: they are known to react very rapidly and quantitatively with sulfhydryl groups over a broad $\mathrm{pH}$ range to form disulfide bounds [45]. Since vitamin B3 (nicotinamide/nicotinic acid) has this structure and a low toxicity, 2 of its derivatives were used as protective substructures: 6-mercaptonicotinamide (6-MNA) and 2-mercaptonicotinic acid (2-MNA). For example, Iqbal et al. described a method in 2 steps: 2-MNA was first oxidized to dimer and then it was 
coupled to PAA-Cys via a disulfide exchange reaction to give a conjugate (PAA-Cys-MNA). This method was used in other studies [23; 46-50]. Besides, a quite similar methods was described with 6MNA [45].

\subsection{Thiomers as drugs: S-nitrosothiomers}

Thiomers are not only used as drug excipients but can also be used as drugs. Because thiomers have free thiol (-SH) groups, active groups can be attached to these thiols for their therapeutic activities. Nitric oxide (NO) is an endogenous molecule and is a free radical having a very short half-life in vivo. However, the biological half-life of NO can be increased by its chemical attachment to a free thiol group available on glutathione (GSH), and an NO-donor $S$-nitrosoglutathione (GSNO) is obtained with an increased half-life [24]. Similarly, these NO-donor thiomers can be further linked to polymers for enhanced bioavailability and improved pharmacokinetics. In a study reported by Katsumi et al., a NOdonor was synthesized by the chemical attachment of SATA ( $N$-succinimidyl-S-acetylthioacetate) to polyethylene glycol (PEG) and bovine serum albumin [51]. More recently, a new NO-donor was synthesized by the covalent attachment of chitosan to GSNO [24] and alginate to GSNO [24], with better values observed for NO-linked to the polymer backbone.

Consequently, a variety of thiomers can be modified to achieve desired properties and therapeutic effects using simple reactions with minimal steps.

\section{Properties of thiolated polymers}

\subsection{Mucoadhesive properties}

Various research groups have verified the mucoadhesive properties of first generation thiomers for many polymer backbones, showing a more than 100-fold enhancement of mucoadhesive properties. For instance, the mucoadhesive properties of chitosan were enhanced 140 -fold by the immobilization of thiol groups [38]. Thiomers, in contrast with other polymers, are proficient at developing covalent bonds with Cys-rich glycoprotein subdomains through thiol/disulfide interchange reactions. The produced covalent linkages are reportedly much stronger than the non-covalent polymer-anionic substructure interactions of the mucous layer [8]. 
As depicted in table 1, in contrast with unchanged polymers, the thiomers show stronger adhesion, thus leading to increased oral bioavailability, subsequent reductions in dosing frequency and increased patient compliance [52].

Insert Table 1

\subsection{Permeation enhancement}

Different approaches have been taken to overcome absorption barriers, primarily through the use of permeation enhancers [56]. Different classes of low-molecular weight permeation enhancers, such as ethylene-diamine-tetraacetic acid (EDTA) and phospholipids, have been confirmed to be valuable in enhancing the permeation of crosswise integral epithelial membranes [57]. On the other hand, permeation and bioavailability also depend on a drug's physicochemical properties [58]. In addition to the physicochemical properties of the drug, bioavailability also depends on formulation design and GIT's physiological conditions [59]. Some other factors affecting bioavailability include enzymes, transit time, food material and other drugs [60]. In most circumstances, inadequate uptake from the mucosa is the main obstacle to the oral bioavailability of hydrophilic macromolecules, and this mucosal uptake can be favored by either trans-cellular or para-cellular routes of administration [35]. Thiomers, compared with most low-molecular weight permeation enhancers, provide the benefit of not being absorbed by the mucosal membrane and thus maintain their permeation enhancement properties for long periods of time [4]. The most probable mechanism for this enhanced permeation has been credited to claudin and occludin proteins present in tight junctions that regulate cell adhesion and ion selection [60-62]. This mechanism further proposes that inhibition of the enzyme PTP is responsible for the dephosphorylation of the tyrosine subunits of occludin, leading to the opening and closing of tight junctions and hence a greater permeation-enhancing effect. The phosphorylation and opening of tight junctions is caused by compounds such as reduced GSH, but due to fast oxidation on the mucosal membrane, its effect is restricted [8]. The presence of thiolated polymers on the mucosal surface to prevent the oxidation of GSH is vital. Many thiomers, such as PAA-Cys [63], polycarbophil-Cys (PCP-Cys) [64], CS-TGA [65] and CMC-Cys, have been reported to have a greater permeation-enhancing influence on some in vitro model compounds, as shown in table 2. The degree of thiolation has also been reported to have a significant impact on permeation-enhancement properties $[63 ; 66]$. We can simply assume that the higher the degree of thiolation, the higher the permeation-enhancement effect. 


\subsection{Efflux pump inhibiting properties}

The ATP binding layer belongs to a superfamily of transmembrane-situated transporter proteins known as $\mathrm{ABC}$, including P-Glycoprotein (Pgp) and multidrug-resistance protein in apical enterocytes membrane (MRP2), which are known to be efflux pumps. These pumps are the limiting factors for the oral bioavailability of many drugs and are involved in xenobiotic transport of nutrients etc. back from the serosa to the mucosa of epithelial tissue (out of the cell membrane), thus acting as a protective shield [8; 69; 70]. Cationic drugs are largely blocked by Pgp, whereas in contrast, anionic drugs are usually effluxed by MRP2. Therefore, the inhibition of these transport proteins is of high interest and has been accomplished by the use of polymers, such as thiomers, polyethylene-glycols (PEG)[71] and pluronic block copolymers [72], which restrict transport by the formation of disulfide linkages [73]. Palmberger et al. investigated the effect of thiolated anionic biopolymers in vitro and in vivo as efflux inhibitors to improve intestinal trans-cellular drug uptake. Three thiomers, pectin-cysteine (Pect-Cys), carboxymethylcellulose-cysteine (CMC-Cys) and ALG-Cys, were synthesized and tested on rat small intestine using sulforhodamine 101 (SR-101) as the MRP2 model substrate. It was found that SR-101 transport in the presence of Pect-Cys, CMC-Cys and ALG-Cys improved by 1.5, 1.8 and 3.0-fold, respectively, in vitro; unmodified alginate improved by 3.8-fold, and the $\mathrm{AUC}_{0 \geq 12}$ of SR-101 improved by a factor of 1.9 in vivo. It was suggested that thiolated alginate can act as a favorable auxiliary agent for different drugs by being an anionic efflux pump substrate, thereby greatly enhancing oral MRP2 substrate bioavailability [74]. Grabovac et al. investigated the effect of the molecular mass and thiol group content of poly (acrylic acid) - cysteine conjugates (PAA-Cys) on sulforhodamine and penicillin G permeation by acting as an MRP2 efflux pump inhibitor in rat small intestine. Using a 250-kDa PAA-Cys conjugate, sulforhodamine exhibited a 3.85-fold permeability improvement from 3.93 to $355.9 \pm 39.5 \mu \mathrm{mol} / \mathrm{g}$, and penicillin G exhibited a 1.59-fold improvement. It was proposed that thiolated PAA constrains MRP2mediated transport and that the extent of inhibition was dependent upon molecular mass and the amount of polymer thiolation [32].

\subsection{In situ gelling properties}

An important limiting factor for a drug's efficacy is rapid clearance from the site of drug administration, whether ocular, nasal or vaginal mucosa. It has been generally accepted that bioavailability of drug moieties can be enhanced by increasing the drug's viscosity and subsequently limiting its clearance. In situ-based drug formulation is hence a very favorable approach to acquiring drug formulations of the 
desired viscosity [62]. As a consequence of some physicochemical changes due to the physiological environment such as temperature [75-77], $\mathrm{pH}$ [78-80], electrolyte concentrations [81-83] and the formation of inter- and/or intra-molecular disulfide bonds by oxidation, extensive crosslinking results in sol-to-gel transitions. Hintzen et al. synthesized three thiomers, i.e., pectin-cysteine (Pec-Cys), sodium carboxymethylcellulose-cysteine (NaCMC-Cys) and poly(acrylic acid)-cysteine (PAA-Cys), and measured the rheological properties of $1 \%(\mathrm{~m} / \mathrm{v})$ thiomer solutions with oxidizing agents and compared the oscillatory measurements over time $(120 \mathrm{mn})$. It was observed that Pec-Cys and NaCMC-Cys with carbamide peroxide and hydrogen exhibited a 13,000-fold increase in dynamic viscosity, and the reason for the increase in viscosity was attributed to the formation of inter- and/or intra-molecular disulfide linkages [84]. It was also found that thiomers exhibiting a polysaccharide backbone showed significant viscosity increases $(\mathrm{p}<0.05)$ [85]. Gyarmati et al. investigated in situ gelling poly(aspartic acid) (PASA) thiomers to determine their potential in the development of injectable preparations. It was found that time of gelation and gel strength were related to polymer concentration, but the time of gelation was controlled independently of gel strength by changing the oxidizing agent concentration. Gelation time could be altered by between 2-6 min, making thiomer PASP a good candidate for injectable drug delivery formulations [3]. In another study, Iqbal et al. measured the viscoelastic properties of poly(acrylic acid)cysteine-mercaptonicotinamide (PAA-Cys-2MNA; 100, 250 and $450 \mathrm{kDa}$ ), related thiomers and unmodified PAAs in pH 6.8 phosphate buffer. It was found that with an increase in molecular mass and pre-activation of thiolated PAAs, the dynamic viscosity was enhanced [22]. The obtained results thus confirm the hypothesis that an increase in the proportionality of viscosity is associated with molecular mass and the number of sulfhydryl moieties on the polymer [86]. Table 3 depicts a comparison of some of the dynamic viscosity improvement ratios of various thiomers in the presence of mucous.

Insert Table 3

\section{Different routes of drug administration using thiomers as drug carriers}

\subsection{Oral matrix tablets}

Different routes of drug administration with thiomers as a carrier have emerged in the past few years. Among these, the oral route is considered the safest and most effective route of drug administration [88]. Matrix tablets with mucoadhesive thiomers show great potential for oral, intra-oral and vaginal drug administration $[40 ; 47 ; 55 ; 63 ; 89]$. The swollen polymer matrix offers enhanced stability and cohesiveness in situ because of inter- and intra-molecular disulphide bond generation [66]. Disintegration studies performed on tablets with PAA in its modified and un-modified thiolated forms to investigate 
Expert Opinion on Drug Delivery - http://dx.doi.org/10.1080/17425247.2016.1227787

overall stability revealed that tablets with un-modified polymer disintegrated within $2 \mathrm{~h}$, whereas for those with PAA-Cys, no disintegration was observed after $48 \mathrm{~h}$ [90]. The swelling properties of matrix tablets can be reduced by the incorporation of a hydrophobic ligand such as oxidized MNA, providing preactivated polymers [45]. This protection is very significant for prolonging mucoadhesion [35; 91] because thiolated polymers, upon excessive water uptake, attain unnecessary weight and cause the detachment of matrix tablets from the mucosal surface. In another study, the oral bioavailability of antide tablets (i.e., a peptide that acts as an LHRH antagonist), including both thiolated and S-protected thiolated chitosan, was assessed. If the antide is incorporated in chitosan-thioglycolic acid-6-mercaptonicotinic acid (CS-TGA-MNA), the peptide reaches an absolute bioavailability of $1.4 \%$, resulting in a 421 -fold increased area under the plasma concentration time curve compared with the antide solution [23; 35; 45]. In a follow-up study, the potential of a preactivated thiolated pectin derivative (Pec-Cys-MNA) to act as a mucoadhesive excipient for gastric cavity delivery was assessed. Mini-tablets were developed and evaluated for mucoadhesion, disintegration, swelling and release of rosuvastatin calcium. Adhesion increased by more than 5-fold, disintegration time was prolonged by more than 2-fold, weight gain for Pec-Cys-MNA was at least 16-fold higher, and sustained release of rosuvastatin calcium was observed over $36 \mathrm{~h}$ [47].

\subsection{Microparticles and nanoparticles}

Multiple unit dosage forms such as micro- and nanoparticles, in contrast with single unit dosage forms such as tablets, have extended residence time in small intestine [23]. In one study, the tablet formulation left the small intestine completely after $3 \mathrm{~h}$, whereas in the case of particles, more than 50\% were still present after the same time [92]. Barthelmes et al. revealed that thiolated nanoparticles have enhanced mucoadhesive properties compared with unmodified nanoparticles on intravesical mucosa [93]. Lee et al., during studies on the transfection efficiency of chitosan-4-thiobutylamidine (CS-TGA/DNA) nanoparticles, observed that higher gene expression was induced by these thiolated chitosan nanoparticles (TCS-NPs) compared with unmodified chitosan nanoparticles (CS-NPs); CS-TGA/DNA with crosslinking nanoparticles exhibited prolonged DNA release and, after transfection, uninterrupted expression for up to $60 \mathrm{~h}$ [94]. Bari et al. conducted an in vivo evaluation of thiolated chitosan nanoparticles (TCS-NPs) of buspirone hydrochloride (BUH) for delivery into the brain through the intranasal route using bovine nasal cavity tissue. It was found that TCS-NPs had 15\% more binding efficiency than unmodified CS-NPs, which could be due to the low amount of CS and TCS interacting with mucin, increased particle size of BUH-loaded CS and TCS nanoparticles and absorption of drug molecules on the NP surface, leading to low NP mucosal layer penetration [27]. Improved TCS binding 
efficiency could be due to covalent attachment of TGA to CS generating a thiol group that interacts with mucin [37]. After $12 \mathrm{~h}$, the cumulative \% of drug permeated through the nasal mucosa by CS-BUH-NPs and TCS-BUH-NPs was found to be 62.52 and $76.21 \%$, whereas $20.97 \%$ permeated from pure drug solution, as depicted in figure 3a. The formulation (i.e. TCS-BUH-NPs) was also tested in vivo in Wistar rats: a comparatively higher brain concentration $(797.46 \pm 35.76 \mathrm{ng} / \mathrm{ml}$; tmax $120 \mathrm{~min})$ was achieved after intranasal administration of TCS-NPs compared with that achieved after nasal administration of the pure drug solution (417.77 $\pm 19.24 \mathrm{ng} / \mathrm{ml}$; tmax $60 \mathrm{~min}$ ), as shown in the figure $3 \mathrm{~b}$ [27] .

Insert Figure 3a - Insert Figure 3b

\section{Gels, liquids and other routes}

Thiolated liquid formulations are commonly used in ocular [95-97] and nasal [98-101] preparations, as low viscosity formulations are very easy to introduce and more tempting esthetically for patients. Due to comparatively higher viscosity, hydrogels provide a sustained residence time at the site of application; therefore, lidocaine hydrogels for buccal delivery using preactivated thiolated pectin were developed, and a sustained release of lidocaine was observed [55]. Laffleur et al. modified hyaluronic acid with cysteine ethyl ester (HA-Cys-EE) for the treatment of dry eye syndrome and showed a 3.81-fold increase in swelling capacity, 30.5-fold improvement in mucoadhesion and 9.72-fold higher stability [102]. Hintzen et al. synthesized $S$-protected thiolated pectin (Pec-Cys-MNA) resistant to oxidation in solutions above $\mathrm{pH}$ 5. The obtained results depicted a 1.8 -fold increase in disintegration time at $\mathrm{pH} 6.8$ and a 6.7 -fold increase in dynamic viscosity compared with unmodified pectin. Long-term stability for a liquid formulation based on Pec-Cys-MNA was also demonstrated in a 6-month experiment [103]. In another study, thiolated polydimethylaminoethylmethacrylate (PDCys) was synthesized and exhibited higher force and work of adhesion and a 3.9-fold permeation improvement in Caco-2 cells compared with the parent polymer [104]. Similar results were found in follow-up studies [22; 85; 105]. In a study on enhanced vaginal mucoadhesion, hyaluronic acid was thiolated and then pre-activated with 6mercaptonicotinamide to develop HA-Cys-MNA. Prolonged mucoadhesion, higher stability (3.6-folds prolonged disintegration time) and no toxicity were observed [29].

\section{Conclusion}

This review shows that there are many possibilities to produce thiomers. These thiomers are promising excipient for the development of novel formulations including tablets, microparticles 
and nanoparticles. Actually, thiolation dramatically increase very specific properties: in drug delivery, mucoadhesion, efflux inhibition, permeation enhancement and in situ gelation are the advantageous properties of these thiomers. Due to their properties, -SH groups can in turn link to other compounds and give rise to preactivated thiomers. Finally, thiomers have been used to produce NO-donors, which we have named $S$-nitrosothiomers. These polymers are potential drugs and have been proposed for the treatment of Crohn's disease.

\section{Expert opinion}

Synthesis of thiomers is realized by linkage of sulhydryl bearing compounds (SBC). Several methods have been published leading to a wide selection of polymers.

Although this review can help to compare each of these polymers, making a choice can be a complex matter. The number of-SH groups and the variations of « ratio of improvement » that have been studied are important parameters but physiochemical parameters (e.g. viscosity, hydrophilicity, ability to produces particles tablets or gels, etc.) are also critical for the final formulations. In most studies, polymers are partially modified and the final thiomers could be easily compared to the starting compound: similar formulations are usually made with the thiomer and its corresponding unmodified polymer.

To date, some toxicological data show that thiomers don't show more in vitro cytotoxicity than unmodified polymers [84]. Even preactivated polymers that can release 2-MNA or 6-MNA did not show more toxicity [105].

For a further development, it is important to take in account that thiomers usually correspond to mixtures of various structures. For example, oxidation of the free thiols can lead to the formation of disulfide bounds [84] and an increased viscosity. In many cases, the oxidized thiomers have been reduced by $\mathrm{NaBH}_{4}$ [24]. This method can give « $100 \%$-free thiols » polymers but add another step for the production of thiomers and a necessity to purify the formulation from $\mathrm{NaBH}_{4}$.

Additively, if amino acids are used as SBC, other unintended reactions can occur [36] leading to the formation of chains of 2, 3 or more amino acids. Nevertheless this kind of reaction should be put in perspective, as yield of the reaction (i.e. SBC linkage) is usually low. At a first sight, these action are not considered to be an issue but this might lead to variations in molecular weights and physicochemical 
properties. The use of a protecting group (also used for the synthesis of peptides) has never been tested but could probably better control the reaction of amino acids. Traut's reactant doesn't have this shortcoming.

However, obtained polymers have very interesting properties; higher degrees of modification are probably not necessary and would lead to extreme changes in properties. After rigorous characterization, they can be considered promising tools in the development of different formulations. To overcome the challenges faced in the field of drug delivery (e.g., poor bioavailability), the use of these multifunctional polymeric excipients may be a favorable approach.

To date, a medical device (Lacrimera ${ }^{\circledR}$ : chitosan-N-acetylcysteine conjugate) has been marketed and proposed in the treatment of dry eye syndrome. 


\section{References}

$*=$ of interest, $* *$ of considerable interest

1. Gyarmati B, Némethy Á, Szilágyi A. Reversible disulphide formation in polymer networks: A versatile functional group from synthesis to applications. Eur Polym J 2013; 49: 1268-86

2. Bacalocostantis I, Mane VP, Kang MS, et al. Effect of Thiol Pendant Conjugates on Plasmid DNA Binding, Release, and Stability of Polymeric Delivery Vectors. Biomacromolecules 2012; 13: 1331-39

3. Gyarmati B, Krisch E, Szilágyi A. In situ oxidation-induced gelation of poly(aspartic acid) thiomers. React Funct Polym 2014; 84: 29-36

4. Samuel AJ, Kulkarni M, Tambe R. Thiomers: Forms, features and formulations. J Chem Pharm Res 2010; $2: 316-23$

5. Li C, Guo T, Zhou D, et al. A novel glutathione modified chitosan conjugate for efficient gene delivery. J Controlled Release 2011; 154: 177-88

6. Jin X, Xu Y, Shen J, et al. Chitosan-glutathione conjugate-coated poly(butyl cyanoacrylate) nanoparticles: Promising carriers for oral thymopentin delivery. Carbohydr Polym 2011; 86: 51-57

7. Bernkop-Schnürch DA, Greimel A. Thiomers. Am J Drug Deliv 2005; 3: 141-54

** Interesting revew on thiomers

8. Laffleur F, Bernkop-Schnürch A. Thiomers: promising platform for macromolecular drug delivery. Future Med Chem 2012; 4: 2205-16

9. Brannon-Peppas L, Blanchette JO. Nanoparticle and targeted systems for cancer therapy. Adv Drug Deliv Rev 2004; 56: 1649-59 
10. Balenga NAB, Zahedifard F, Weiss R, et al. Balenga, N. A. et al. Protective efficiency of dendrosomes as novel nano-sized adjuvants for DNA vaccination against birch pollen allergy. J. Biotechnol. 124, 602-614. J Biotechnol 2006; 124: 602-14

11. Kafedjiiski K, Jetti RK, Foger F, et al. Synthesis and in vitro evaluation of thiolated hyaluronic acid for mucoadhesive drug delivery. Int J Pharm 2007; 343: 48-58

12. Shen J, Wang Y, Ping Q, et al. Mucoadhesive effect of thiolated PEG stearate and its modified NLC for ocular drug delivery. J Controlled Release 2009; 137: 217-23

13. Cuenca AG, Jiang H, Hochwald SN, et al. Emerging implications of nanotechnology on cancer diagnostics and therapeutics. Cancer 2006; 107: 459-66

14. Laffleur F, Bernkop-Schnürch A. Strategies for improving mucosal drug delivery. Nanomedicine 2013; 8: 2061-75

15. Müller RH, Mäder K, Gohla S. Solid lipid nanoparticles (SLN) for controlled drug delivery - a review of the state of the art. Eur J Pharm Biopharm 2000; 50: 161-77

16. Bhattarai N, Gunn J, Zhang M. Chitosan-based hydrogels for controlled, localized drug delivery活. Adv Drug Deliv Rev 2010; 62: 83-99

17. Langguth P, Hanafy A, Frenzel D, et al. Nanosuspension Formulations for Low-Soluble Drugs: Pharmacokinetic Evaluation Using Spironolactone as Model Compound. Drug Dev Ind Pharm 2008; 31 : 319-29

18. Kumar R, Sinha VR. Thiomer: A potential carrier for therapeutic delivery. React Funct Polym 2013; 73: 1156-66

** Interesting review on thiomers 
19. Wong HL, Rauth AM, Bendayan R, et al. A new polymer-lipid hybrid nanoparticle system increases cytotoxicity of doxorubicin against multidrug-resistant human breast cancer cells. Pharm Res 2006; 23: $1574-85$

20. Walsh EG, Adamczyk BE, Chalasani KB, et al. Oral delivery of macromolecules: Rationale underpinning Gastrointestinal Permeation Enhancement Technology (GIPET®). Ther Deliv 2011; 2: $1595-610$

21. Hauptstein S, Bernkop-Schnürch A. Thiomers and thiomer-based nanoparticles in protein and DNA drug delivery. Expert Opin Drug Deliv 2012; 9: 1069-81

22. Iqbal J, Shahnaz G, Dünnhaupt S, et al. Preactivated thiomers as mucoadhesive polymers for drug delivery. Biomaterials 2012; 33: 1528-35

23. Bonengel S, Haupstein S, Perera G, et al. Thiolated and S-protected hydrophobically modified crosslinked poly(acrylic acid) - A new generation of multifunctional polymers. Eur J Pharm Biopharm 2014; 88: $390-96$

\section{* This article describe the protection of thiomers}

24. Shah SU, Martinho N, Socha M, et al. Synthesis and characterization of S-nitrosoglutathioneoligosaccharide-chitosan as a nitric oxide donor. Expert Opin Drug Deliv 2015; 12: 1209-23

25. Shah SU, Socha M, Fries I, et al. Synthesis of S-nitrosoglutathione-alginate for prolonged delivery of nitric oxide in intestines. Drug Deliv 2015; 1-9

26. Palmberger T, Hombach J, Bernkop-Schnürch A. Thiolated chitosan: Development and in vitro evaluation of an oral delivery system for acyclovir. Int J Pharm 2008; 348: 54-60

27. Bari NK, Fazil M, Hassan MQ, et al. Brain delivery of buspirone hydrochloride chitosan nanoparticles for the treatment of general anxiety disorder. Int J Biol Macromol 2015; 81: 49-59 
28. Laffleur F, Bacher L, Vanicek S, et al. Next generation of buccadhesive excipient: Preactivated carboxymethyl cellulose. Int J Pharm 2016; 500: 120-27

29. Nowak J, Laffleur F, Bernkop-Schnürch A. Preactivated hyaluronic acid: A potential mucoadhesive polymer for vaginal delivery. Int J Pharm 2015; 478: 383-89

30. Duggan S, O'Donovan O, Owens E, et al. Synthesis of mucoadhesive thiolated gelatin using a twostep reaction process. Eur J Pharm Biopharm 2015; 91: 75-81

31. Albrecht K, Bernkop-Schnürch A. Thiomers: forms, functions and applications to nanomedicine. Nanomedicine 2007; $2: 41-50$

32. Grabovac V, Laffleur F, Bernkop-Schnürch A. Thiomers: Influence of molecular mass and thiol group content of poly(acrylic acid) on efflux pump inhibition. Int J Pharm 2015; 493: 374-79

33. Deepak K, Kumar MS, Mahadevan N. Thiolated chitosan: modified advanced generation of mucoadhesive polymers. Int J Recent Adv Pharm Res 2012; 2: 31-41

34. Millotti G, Samberger C, Fröhlich E, et al. Chitosan-graft-6-mercaptonicotinic Acid: Synthesis, Characterization, and Biocompatibility. Biomacromolecules 2009; 10: 3023-27

35. Ijaz M, Bernkop-Schnürch A. Preactivated thiomers: their role in drug delivery. Expert Opin Drug Deliv 2015; 12: 1269-81

36. Riniker B. Protection of Functional Groups in Peptide Synthesis. Metabolism 1964; 13: SUPPL:103242

37. Kast CE, Bernkop-Schnürch A. Thiolated polymers - thiomers: development and in vitro evaluation of chitosan-thioglycolic acid conjugates. Biomaterials 2001; 22: 2345-52

\footnotetext{
* This artcle shows the development of chitosan-thioglycolic acid conjugates
} 
38. Bernkop-Schnurch A. Thiolated polymers - thiomers: synthesis and in vitro evaluation of chitosan-2iminothiolane conjugates. Int J Pharm 2003; 260: 229-37

* This article show the development of chitosan-2-iminothiolane conjugates

39. Kafedjiiski K, Krauland AH, Hoffer $\mathrm{MH}$, et al. Synthesis and in vitro evaluation of a novel thiolated chitosan. Biomaterials 2005; 26: 819-26

40. Hanif M, Zaman M, Qureshi S, et al. Thiomers: A Blessing to Evaluating Era of Pharmaceuticals. Int J Polym Sci 2015; 2015: 1-9

41. Madgulkar AR, Bhalekar MR, Asgaonkar KD, et al. Synthesis and characterization of a novel mucoadhesive derivative of xyloglucan. Carbohydr Polym 2016; 135: 356-62

* This article describes the syntheis of a derivative of xyloglucan

42. Bhalekar MR, Bargaje RV, Upadhaya PG, et al. Formulation of mucoadhesive gastric retentive drug delivery using thiolated xyloglucan. Carbohydr Polym 2016; 136: 537-42

43. Rahmat D, Sakloetsakun D, Shahnaz G, et al. Design and synthesis of a novel cationic thiolated polymer. Int J Pharm 2011; 411: 10-17

44. Sarti F, Staaf A, Sakloetsakun D, et al. Thiolated hydroxyethylcellulose: Synthesis and in vitro evaluation. Eur J Pharm Biopharm 2010; 76: 421-27

* This article described the synthesis of thiolated hydroxycellulose

45. Dünnhaupt S, Barthelmes J, Thurner CC, et al. S-protected thiolated chitosan: Synthesis and in vitro characterization. Carbohydr Polym 2012; 90: 765-72

46. Hintzen F, Hauptstein S, Perera G, et al. Synthesis and in vitro characterization of entirely S-protected thiolated pectin for drug delivery. Eur J Pharm Biopharm 2013; 85: 1266-73

47. Hauptstein S, Müller C, Dünnhaupt S, et al. Preactivated thiomers: Evaluation of gastroretentive minitablets. Int J Pharm 2013; 456: 473-79 
48. Menzel C, Bonengel S, de Sousa IP, et al. Preactivated thiolated nanoparticles: A novel mucoadhesive dosage form. Int J Pharm 2016; 497: 123-28

49. Menzel C, Silbernagl J, Laffleur F, et al. 2,2'Dithiodinicotinyl ligands: Key to more reactive thiomers. Int J Pharm 2016; 503: 199-206

50. Partenhauser A, Zupančič O, Podričnik S, et al. Entirely S-protected silicone oil as second generation mucoadhesive agent. Eur Polym J 2016; 76: 53-62

51. Katsumi H, Nishikawa M, Yamashita F, et al. Development of polyethylene glycol-conjugated polyS-nitrosated serum albumin, a novel S-Nitrosothiol for prolonged delivery of nitric oxide in the blood circulation in vivo. J Pharmacol Exp Ther 2005; 314: 1117-24

52. Bernkop-Schnürch A, Krauland AH, Leitner VM, et al. Thiomers: potential excipients for noninvasive peptide delivery systems. Eur J Pharm Biopharm 2004; 58: 253-63

53. Laffleur F, Shahnaz G, Islambulchilar Z, et al. Design and in vitro evaluation of a novel polymeric excipient for buccal applications. Future Med Chem 2013; 5: 511-22

54. Laffleur F, Röggla J, Idrees MA, et al. Chemical modification of hyaluronic acid for intraoral application. J Pharm Sci 2014; 103: 2414-23

55. Hauptstein S, Hintzen F, Müller C, et al. Development and in vitro evaluation of a buccal drug delivery system based on preactivated thiolated pectin. Drug Dev Ind Pharm 2014; 40: 1530-37

56. Bernkop-Schnürch A, Clausen A. Biomembrane Permeability of Peptides: Strategies to Improve Their Mucosal Uptake. Mini Rev Med Chem 2002; 2: 295-305 
57. Lee VHL. Protease inhibitors and penetration enhancers as approaches to modify peptide absorption. J Controlled Release 1990; 13: 213-23

58. Lipinski CA, Lombardo F, Dominy BW, et al. Experimental and computational approaches to estimate solubility and permeability in drug discovery and development settings. Adv Drug Deliv Rev 1997; 23: 3-25

59. Huang W, Lee SL, Yu LX. Mechanistic Approaches to Predicting Oral Drug Absorption. AAPS J 2009; 11:217-24

60. Blanquet S, Zeijdner E, Beyssac E, et al. A Dynamic Artificial Gastrointestinal System for Studying the Behavior of Orally Administered Drug Dosage Forms Under Various Physiological Conditions. Pharm Res 2004; 21: 585-91

61. Simon DB, Lu Y, Choate KA, et al. Paracellin-1, a Renal Tight Junction Protein Required for Paracellular Mg2+ Resorption. Science 1999; 285: 103-06

62. Sreenivas SA, Pai KV. Thiolated chitosans: novel polymers for mucoadhesive drug delivery-a review. Trop J Pharm Res 2008; 7: 1077-88

63. Kast CE, Bernkop-Schnurch A. Influence of the molecular mass on the permeation enhancing effect of different poly(acrylates). S.T.P. Pharm Sci 2002; 12: 351-56

64. Clausen AE, Bernkop-Schnürch A. In vitro evaluation of the permeation-enhancing effect of thiolated polycarbophil. J Pharm Sci 2000; 89: 1253-61

65. Bernkop-Schnürch A, Guggi D, Pinter Y. Thiolated chitosans: development and in vitro evaluation of a mucoadhesive, permeation enhancing oral drug delivery system. J Controlled Release 2004; 94: 177-86 
66. Clausen AE, Bernkop-Schnurch A. In vitro evaluation of matrix tablets based on thiolated polycarbophil. Pharm Ind 2001; 63: 312-17

67. Barthelmes J, Dünnhaupt S, Hombach J, et al. Thiomer nanoparticles: Stabilization via covalent crosslinking. Drug Deliv 2011;

68. Mahmood A, Bonengel S, Laffleur F, et al. An in-vitro exploration of permeation enhancement by novel polysulfonate thiomers. Int J Pharm 2015; 496: 304-13

69. Werle M. Natural and Synthetic Polymers as Inhibitors of Drug Efflux Pumps. Pharm Res 2007; 25: 500-11

70. Silverman JA. Multidrug-Resistance Transporters. In: Membrane Transporters as Drug Targets. Boston: Springer US; 2002. p. 353-86

71. Hugger ED, Audus KL, Borchardt RT. Effects of poly(ethylene glycol) on efflux transporter activity in Caco-2 cell monolayers. J Pharm Sci 2002; 91: 1980-90

72. Kabanov AV, Batrakova EV, Miller DW. Pluronic ${ }^{\circledR}$ block copolymers as modulators of drug efflux transporter activity in the blood-brain barrier. Adv Drug Deliv Rev 2003; 55: 151-64

73. Jha S, Karnani N, Lynn AM, et al. Covalent modification of cysteine 193 impairs ATPase function of nucleotide-binding domain of a Candida drug efflux pump. Biochem Biophys Res Commun 2003; 310 : 869-75

74. Palmberger TF, Laffleur F, Greindl M, et al. In vivo evaluation of anionic thiolated polymers as oral delivery systems for efflux pump inhibition. Int J Pharm 2015; 491: 318-22

75. Edsman K, Carlfors J, Petersson R. Rheological evaluation of poloxamer as an in situ gel for ophthalmic use. Eur J Pharm Sci 1998; 6: 105-12 
76. Bromberg LE. Enhanced nasal retention of hydrophobically modified polyelectrolytes. J Pharm Pharmacol 2001; 53: 109-14

77. Wei G, Xu H, Ding PT, et al. Thermosetting gels with modulated gelation temperature for ophthalmic use: the rheological and gamma scintigraphic studies. J Controlled Release 2002; 83: 65-74

78. Gurny R, Ibrahim H, Buri P. The development and use of in situ formed gels, triggered by pH. In: Biopharmaceutics of Ocular Drug Delivery. Edman P,editor, Boca Raton: CRC Press; 1993. p. 33-58

79. Chenite A, Chaput C, Wang D, et al. Novel injectable neutral solutions of chitosan form biodegradable gels in situ. Biomaterials 2000; 21: 2155-61

80. Srividya B, Cardoza RM, Amin PD. Sustained ophthalmic delivery of ofloxacin from a pH triggered in situ gelling system. J Controlled Release 2001; 73: 205-11

81. Deasy PB, Quigley KJ. Rheological evaluation of deacetylated gellan gum (Gelrite) for pharmaceutical use. Int J Pharm 1991; 73: 117-23

82. Paulsson M, Hägerström H, Edsman K. Rheological studies of the gelation of deacetylated gellan gum (Gelrite $\left.{ }^{\circledR}\right)$ in physiological conditions. Eur J Pharm Sci 1999; 9: 99-105

83. Susan MABH, Kaneko T, Noda A, et al. Ion Gels Prepared by in Situ Radical Polymerization of Vinyl Monomers in an Ionic Liquid and Their Characterization as Polymer Electrolytes. J Am Chem Soc 2005; 127: 4976-83

84. Sakloetsakun D, Hombach JM, Bernkop-Schnurch A. In situ gelling properties of chitosanthioglycolic acid conjugate in the presence of oxidizing agents. Biomaterials 2009; 30: 6151-7 
85. Hintzen F, Laffleur F, Sakloetsakun D, et al. In situ gelling properties of anionic thiomers. Drug Dev Ind Pharm 2012; 38: 1479-85

86. Palmberger TF, Albrecht K, Loretz B, et al. Thiolated polymers: Evaluation of the influence of the amount of covalently attached l-cysteine to poly(acrylic acid). Eur J Pharm Biopharm 2007; 66: 405-12

87. Friedl HE, Dünnhaupt S, Waldner C, et al. Preactivated thiomers for vaginal drug delivery vehicles. Biomaterials 2013; 34: 7811-18

88. Sarti F, Iqbal J, Müller C, et al. Poly(acrylic acid)-cysteine for oral vitamin B12 delivery. Anal Biochem 2012; 420: 13-19

89. Hombach J, Palmberger TF, Bernkop-Schnürch A. Development and in vitro evaluation of a mucoadhesive vaginal delivery system for nystatin. J Pharma Sci 2009; 98: 555-64

90. Bernkop-Schnürch A, Scholler S, Biebel RG. Development of controlled drug release systems based on thiolated polymers. J Controlled Release 2000; 66: 39-48

* A controlled release has been provided by thiolated polymer tablets

91. Mortazavi SA, Smart JD. Factors Influencing Gel-strengthening at the Mucoadhesive-mucus Interface. J Pharm Pharmacol 1994; 46: 86-90

92. Coupe AJ, Davis SS, Wilding IR. Variation in Gastrointestinal Transit of Pharmaceutical Dosage Forms in Healthy Subjects. Pharm Res 1991; 8: 360-64

93. Barthelmes J, Dünnhaupt S, Unterhofer S, et al. Thiolated particles as effective intravesical drug delivery systems for treatment of bladder-related diseases. Nanomedicine 2013; 8: 65-75

94. Lee D, Zhang W, Shirley SA, et al. Thiolated chitosan/DNA nanocomplexes exhibit enhanced and sustained gene delivery. Pharm Res 2007; 24: 157-67 
95. Hornof M, Weyenberg W, Ludwig A, et al. Mucoadhesive ocular insert based on thiolated poly(acrylic acid): development and in vivo evaluation in humans. J Controlled Release 2003; 89: 419-28

96. Wagh MP, Joshi OU, Patel JS, et al. Thiomers: a new generation of mucoadhesive polymers. Res J Pharm Tech 2009;

97. Zambito Y, Colo GD. Thiolated quaternary ammonium-chitosan conjugates for enhanced precorneal retention, transcorneal permeation and intraocular absorption of dexamethasone. Eur J Pharm Biopharm 2010; 75: 194-99

98. Leitner VM, Guggi D, Krauland AH, et al. Nasal delivery of human growth hormone: in vitro and in vivo evaluation of a thiomer/glutathione microparticulate delivery system. J Controlled Release 2004; 100: $87-95$

99. Krauland AH, Guggi D, Bernkop-Schnürch A. Thiolated chitosan microparticles: A vehicle for nasal peptide drug delivery. Int J Pharm 2006; 307: 270-77

100. Shahnaz G, Vetter A, Barthelmes J, et al. Thiolated chitosan nanoparticles for the nasal administration of leuprolide: Bioavailability and pharmacokinetic characterization. Int J Pharm 2012; 428: $164-70$

101. Vetter A, Bernkop-Schnurch A. Nasal delivery of antisense oligonucleotides: in vitro evaluation of a thiomer/glutathione microparticulate delivery system. J Drug Target 2010; 18: 303-12

102. Laffleur F, Dachs S. Development of novel mucoadhesive hyaluronic acid derivate as lubricant for the treatment of dry eye syndrome. Ther Deliv 2015; 6: 1211-19

103. F H, S H, G P, et al. Synthesis and in vitro characterization of entirely S-protected thiolated pectin for drug delivery. Eur J Pharm Biopharm 2013; 85: 1266-73 
Expert Opinion on Drug Delivery - http://dx.doi.org/10.1080/17425247.2016.1227787

104. Sonia TA, Sharma CP. In vitro Evaluation of Thiolated Polydimethylaminoethylmethacrylate Hydrogel Sub-Microparticles for Oral Insulin Delivery. J Biomed Nanotechnol 2013; 9: 590-600

105. Solhi L, Schönbichler SA, Dünnhaupt S, et al. Synthesis and In Vitro Characterization of a Preactivated Thiomer via Polymerization Reaction. Biomacromolecules 2012; 13: 3054-63 


\section{Legends}

Figure 1. Thiolated polymer (Thiomers) with possibilities of further reactions on the $-\mathrm{SH}$ groups

Figure 2. Thiolation of hexosans with sulfhydryl bearing compounds (SBC) - NBS: $N$ Bromosuccimide; PPh3: Triphenylphosphine; $\quad$ EDAC: 1-ethyl-3-(3dimethylaminopropyl)carbodiimide; TGA : thioglycolic acid.

Figure 3. (a) Ex-vivo permeation of optimized CS-NPs and TCS-NPs. (b) Comparative BUH concentration in blood and brain at different time intervals by BUH-TCS-NP solution given intranasally. From [26] 

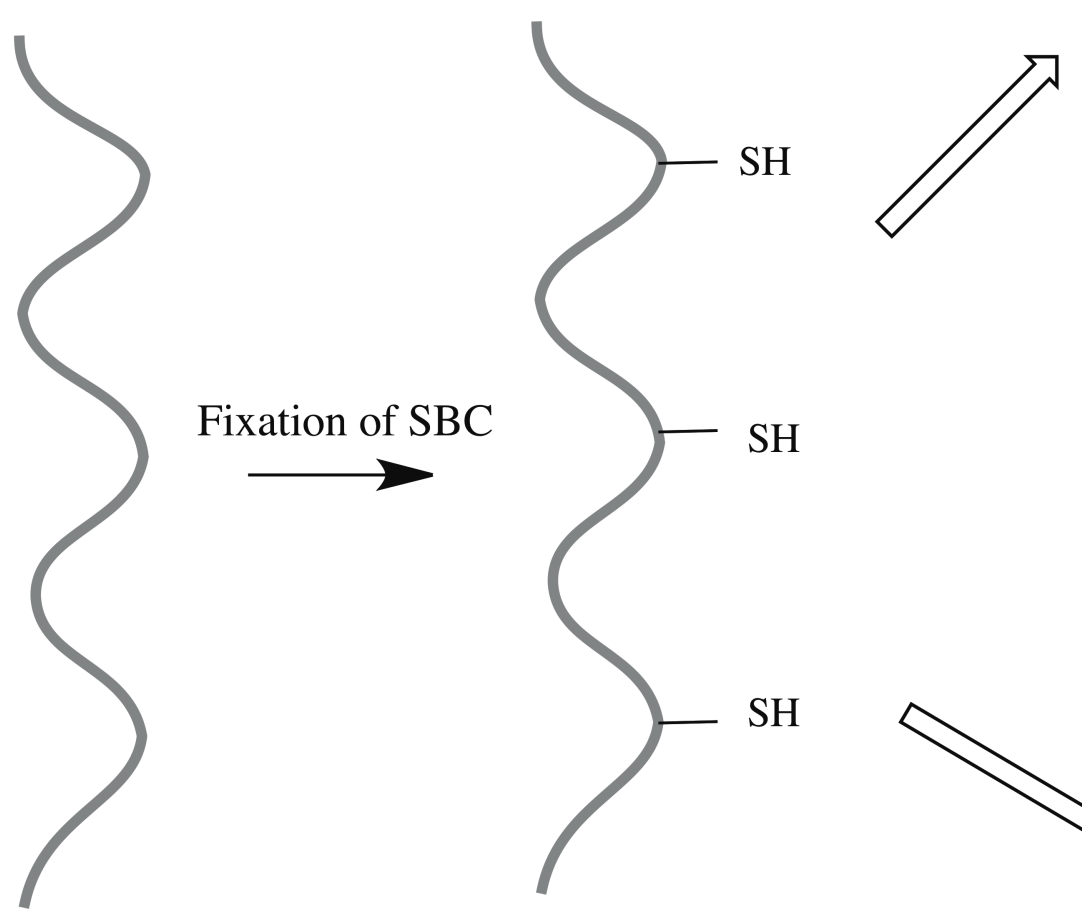

1) Thiomers with free thiols (excipients, mucolytics)

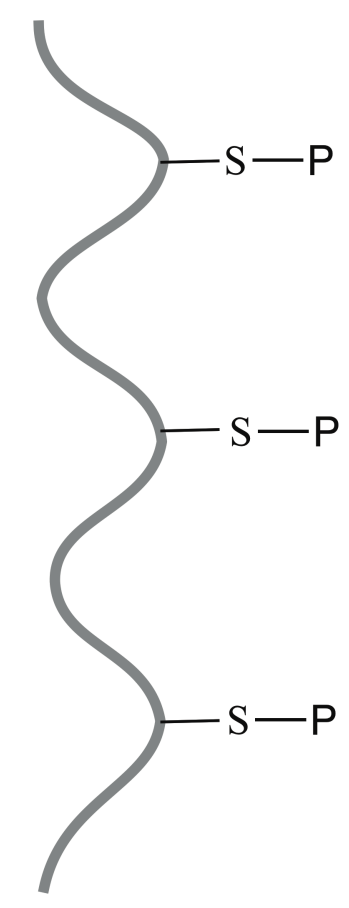

2a) Preactivated thiomers

e.g. $\mathrm{P}=2$-mercaptonicotinic acid

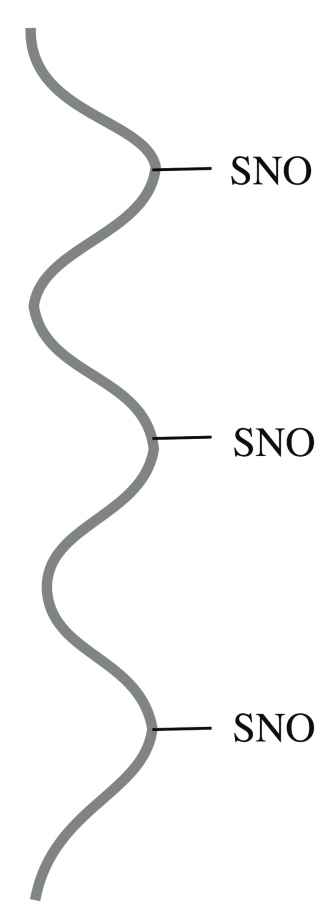

2b) Thiomers as active compounds carrier (prodrugs) e.g. Fixation of NO 

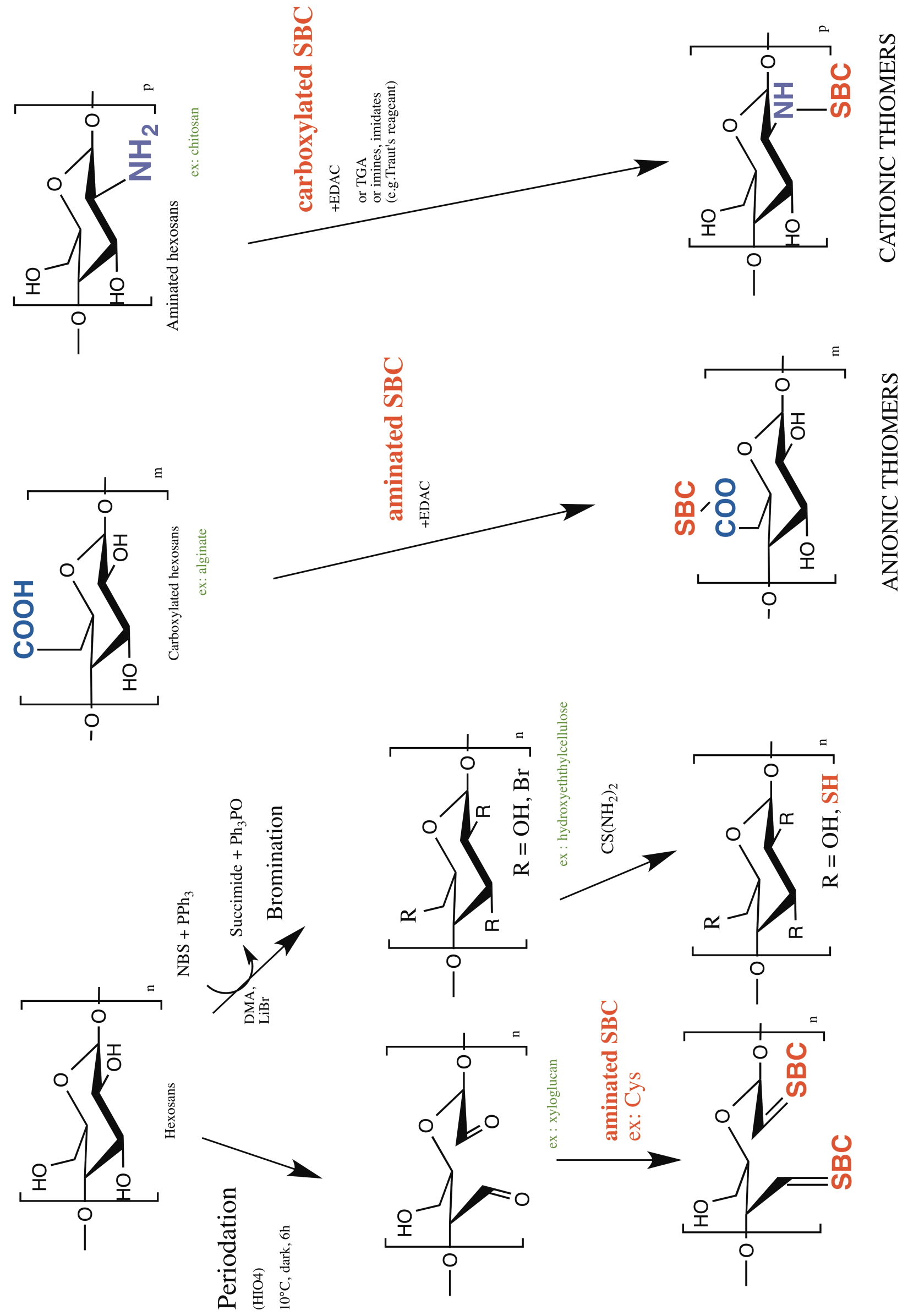


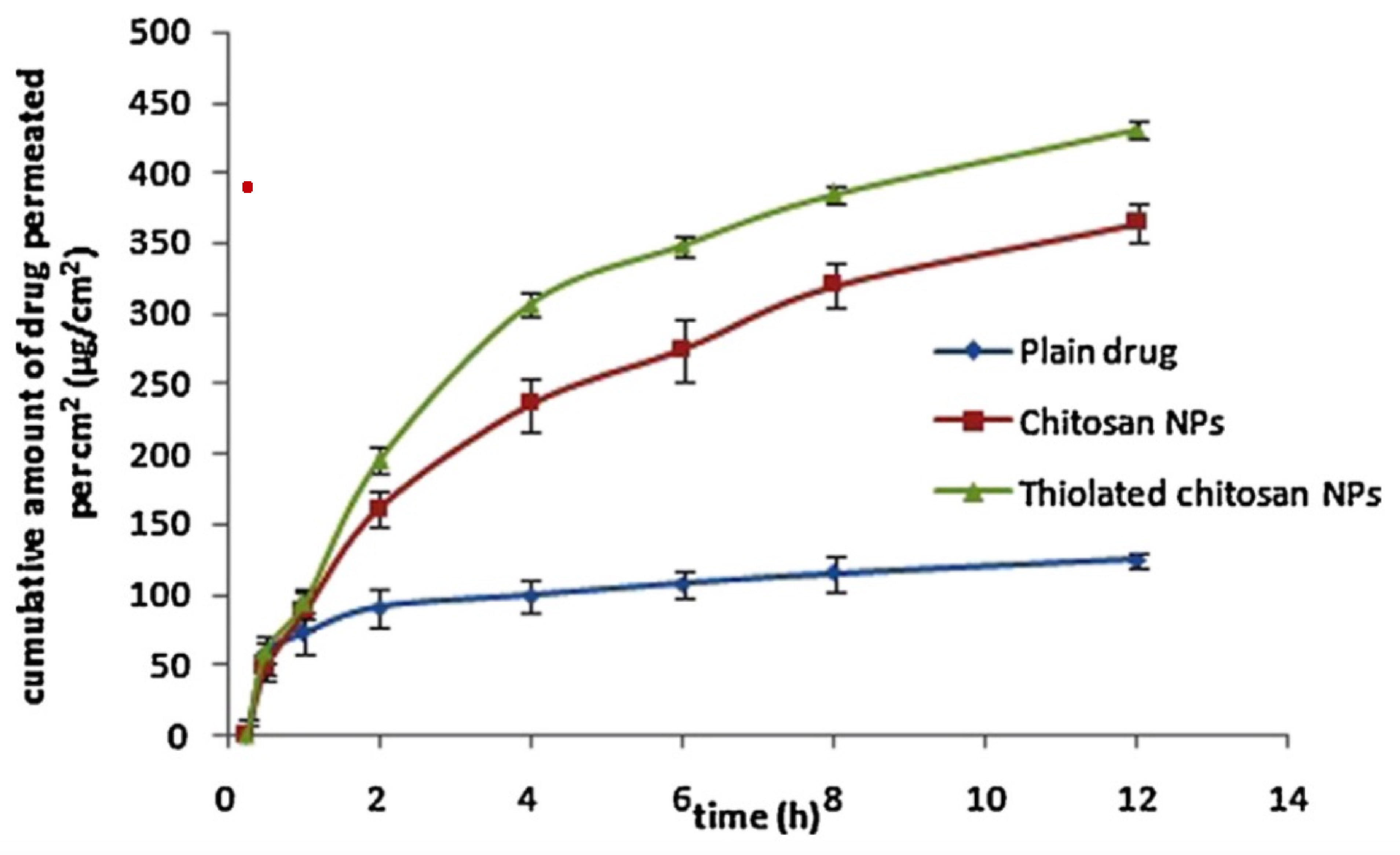




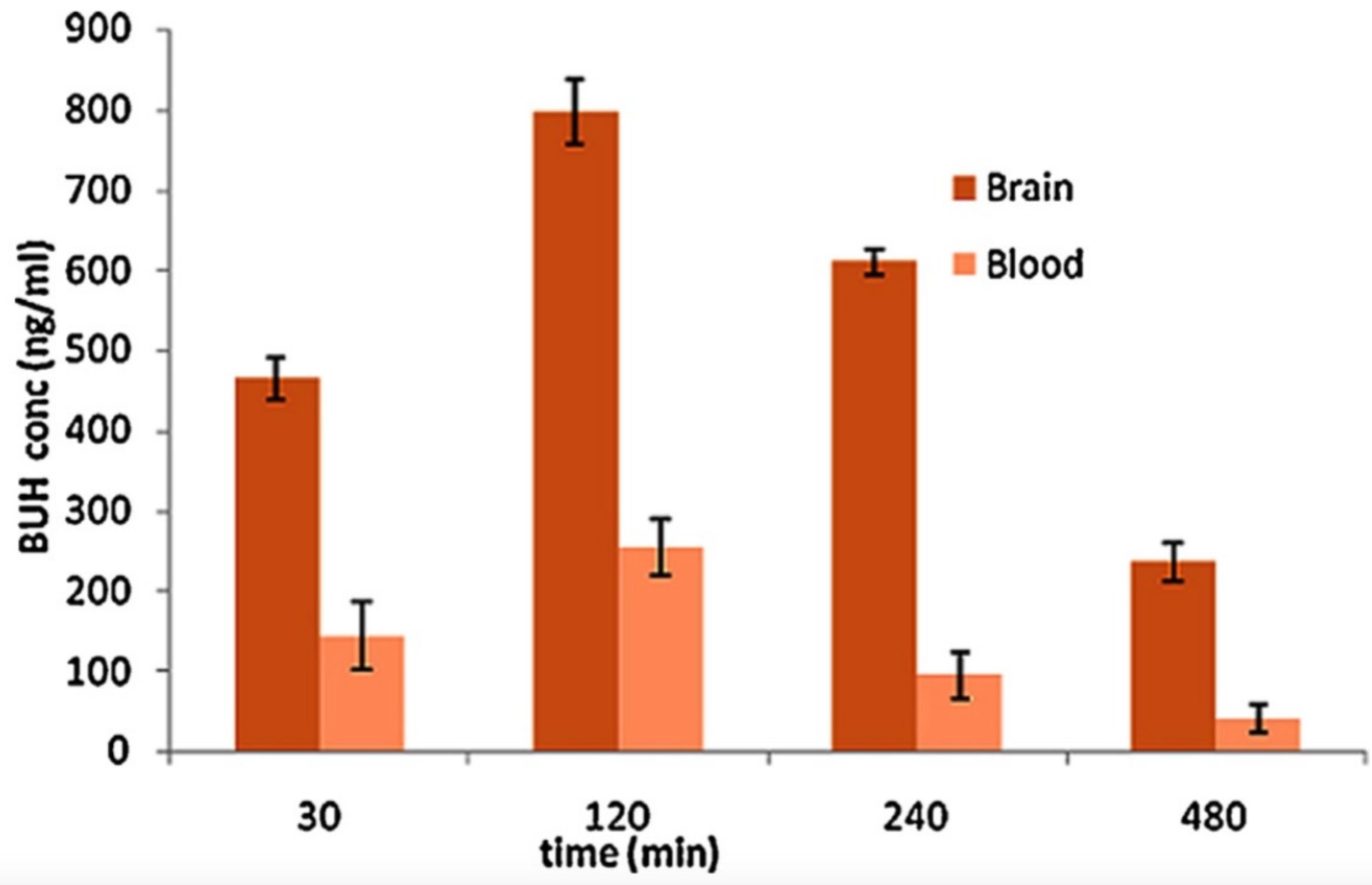


Table 1. Ratio of improvement of thiomers with their original unmodified polymers

\begin{tabular}{|c|c|c|c|c|}
\hline \multirow[t]{2}{*}{ Polymer } & \multirow[t]{2}{*}{ Property } & \multicolumn{2}{|c|}{$\begin{array}{c}\text { Ratio of Improvement of } \\
\text { Polymers }\end{array}$} & \multirow[t]{2}{*}{ Reference } \\
\hline & & $\begin{array}{c}\text { Preactivated } \\
\text { thiomer }\end{array}$ & Thiomer & \\
\hline \multirow[t]{3}{*}{ AC 1030-Cys-2MNA* } & TWA & 5.7 & 3.4 & [23] \\
\hline & Adhesion Time & 18.0 & 4.0 & \\
\hline & MDF & 2.9 & 2.8 & \\
\hline CS-TGA-MNA-660* & Adhesion Time & 9.0 & 1.8 & {$[45]$} \\
\hline \multirow[t]{2}{*}{ CS-TBA-MNA* } & TWA & 79.3 & 14.1 & {$[53]$} \\
\hline & Adhesion Time & 150 & 94.5 & \\
\hline \multirow[t]{2}{*}{ HA-Cys-MNA* } & TWA & 18.0 & 2.8 & {$[54]$} \\
\hline & Adhesion Time & 10.0 & 2.6 & \\
\hline \multirow[t]{2}{*}{ Pec-Cys-MNA* } & TWA & 8.9 & 4.8 & [89] \\
\hline & MDF & 1.6 & 1.8 & \\
\hline \multirow[t]{2}{*}{$\mathrm{PAA}_{450}$-Cys-MNA* } & TWA & 3.0 & 1.9 & {$[22]$} \\
\hline & MDF & 2.5 & 1.4 & \\
\hline
\end{tabular}

AC 1030-Cys-2MNA: Cross-linked hydrophobically modified Poly (acrylic acid) Cysteine- mercaptonicotinamide; CSTGA-MNA-660: Chitosan 660 kDa-thioglycolic acid-mercaptonicotinamide; CS-TBA-MNA: Chitosan-thiobutylamidinemercaptonicotinamide; HA-Cys-MNA: Hyaluronic acid-cysteine ethyl ester-mercaptonicotinamide; Pec-Cys-MNA: Pectincysteine-mercaptonicotinamide; PAA 450 -Cys-MNA: Poly(acrylic acid) $450 \mathrm{kDa}$-cysteine-mercaptonicotinamide; TWA: Total work of adhesion; MDF: Maximum detachment force. *: preactivated polymers 
Table 2. Permeability enhancement in in vitro models and permeability difference between thiomers and their corresponding original polymers

\begin{tabular}{lllll}
\hline Thiomer (Permeation & Test & R Value & Apparent permeability & Ref. \\
Enhancer) & Compound & (Enhancement & Coefficient cm/s $\left(\mathbf{x 1 0}^{-6}\right)$ & \\
& & Ratio) & \\
\hline
\end{tabular}

\begin{tabular}{|c|c|c|c|c|}
\hline \multicolumn{5}{|l|}{ Anionic Thiomers } \\
\hline PCP-Cys & Na-Flu & 1.63 & $11.85 \pm 0.5$ & {$[63]$} \\
\hline PCP-Cys/GSH & Na-Flu & 2.93 & $14.64 \pm 0.93$ & [105] \\
\hline CMC-Cys & Na-Flu & 1.8 & $12.92 \pm 0.41$ & [106] \\
\hline $\mathrm{PAA}_{250}{ }^{-\mathrm{Cys}}-2-\mathrm{MNA}{ }^{*}$ & Na-Flu & 0.81 & $4.68 \pm 0.80$ & {$[66]$} \\
\hline $\mathrm{PAA}_{250}$-Cys-2-MNA/GSH* & Na-Flu & 1.32 & $7.67 \pm 0.23$ & {$[66]$} \\
\hline PSSA-MA & Na-Flu & 1.11 & $2.54 \pm 0.17$ & {$[67]$} \\
\hline PC1608-2MNA* & Na-Flu & 1.60 & $1.00 \pm 0.05$ & {$[67]$} \\
\hline PCP-Cys & SH 101 & 1.27 & $1.60 \pm 0.28$ & {$[32]$} \\
\hline $\mathrm{PAA}_{450}-\mathrm{Cys}$ & SH 101 & 1.95 & $2.41 \pm 0.25$ & {$[32]$} \\
\hline PCP-Cys & Penicillin G & 1.09 & $1.30 \pm 0.31$ & {$[32]$} \\
\hline $\mathrm{PAA}_{450}$-Cys & Penicillin G & 1.17 & $1.41 \pm 0.93$ & {$[32]$} \\
\hline \multicolumn{5}{|l|}{ Cationic Thiomers } \\
\hline CS-TGA-340* & Rhodamine & 2.7 & $3.79 \pm 0.99$ & [107] \\
\hline CS-TGA-980* & Rhodamine & 4.1 & $5.64 \pm 1.15$ & [107] \\
\hline CS-TGA-MNA-340* & Rhodamine & 3.7 & $5.19 \pm 0.93$ & [107] \\
\hline CS-TGA-MNA-980* & Rhodamine & 6.7 & $9.26 \pm 2.30$ & [107] \\
\hline CS-TBA & Rhodamine & 1.8 & $1.5 \pm 0.7$ & {$[64]$} \\
\hline CS-TBA/GSH & Rhodamine & 3.6 & $3.0 \pm 1.2$ & {$[64]$} \\
\hline
\end{tabular}


Table 3. Dynamic viscosity improvement of thiomers

\begin{tabular}{|c|c|c|c|c|}
\hline \multirow[t]{2}{*}{ Polymer } & \multicolumn{2}{|c|}{ Dynamic Viscosity $\eta\left(\mathrm{Pa}^{*} \mathrm{~s}\right)$} & \multirow[t]{2}{*}{ Improvement } & \multirow[t]{2}{*}{ Ref. } \\
\hline & Without Mucus & With Mucus & & \\
\hline Pec-Cys-MNA & $317.68 \pm 33.90$ & $453.95 \pm 64.20$ & 1.4 & {$[89]$} \\
\hline CS-TGA & $56.93 \pm 13.30$ & $417.15 \pm 2.71$ & 7.3 & [87] \\
\hline CS-TGA-MNA & $95.81 \pm 18.63$ & $553.92 \pm 44.34$ & 5.8 & [87] \\
\hline PAA-Cys-2MNA (100 kDa) & $50 \pm 10$ & $55 \pm 10$ & 1.1 & {$[22]$} \\
\hline PAA-Cys-2MNA (250 kDa) & $80 \pm 10$ & $318 \pm 69$ & 4.0 & [22] \\
\hline PAA-Cys-2MNA (450 kDa) & $12860 \pm 80$ & $58872 \pm 3227$ & 4.5 & {$[22]$} \\
\hline
\end{tabular}

Pec-Cys-MNA: Pectin-Cysteine-Mercaptonicotinamide; CS-TGA: Chitosan-Thioglycolic Acid; CS-TGA-MNA: Chitosan-

Thioglycolic Acid-Mercaptonicotinamide; PAA-cys-2MNA: Poly(acrylic acid)-Cysteine-Mercaptonicotinamide. 